\title{
Revitalização e Morte da Civilidade Urbana: Entre a Cidade que não se Garante e os Engajamentos que Favorece $^{1}$
}

\section{Revitalization and Death of Urban Civility: Cetween the City that is not Guaranteed and the Engagements that it Favors}

\section{Manuela Vieira Blanc}

Departamento de Ciências Sociais, Universidade Federal do Espírito Santo, Goiabeiras, Vitória, Espírito Santo, Brasil

\section{RESUMO}

Este artigo analisa os dados coletados ao longo de sete anos de observação de inspiração etnográfica de práticas comunitárias de intervenção no espaço público do Centro da cidade de Vitória, capital do Estado do Espírito Santo. Remontando a história recente do bairro, observamos a emergência de novos parâmetros de normatização do lugar que incidem sobre as intervenções estatais e o engajamento comunitário em iniciativas de requalificação da região. Conferindo destaque para as controvérsias acerca da definição dos problemas públicos do bairro, buscamos compreender os limites para uma participação popular em um contexto político e econômico liberal, o acirramento das disputas internas entre os moradores ao longo do tempo, bem como a inefetividade de uma gestão do espaço voltada exclusivamente para o objetivo de efetivá-lo enquanto simulacro da história e cultura locais, em detrimento de um bairro vivido, onde coexistem uma pluralidade de ideais de bens comuns.

Palavras-chave: Governança por Objetivo, Cidade Garantida, Gramática Liberal dos Interesses Individuais, Problemas Públicos, Associativismo Comunitário.

1 Trabalho desenvolvido no âmbito do projeto Cep 29: Núcleo capixaba de estudos da experiência humana em meio urbano, financiado pelo EDITAL FAPES/CNPq No 022/2018 PROGRAMA DE INFRAESTRUTURA PARA JOVENS PESQUISADORES (PROGRAMA PRIMEIROS PROJETOS - PPP), sob o registro 058/2019.

Recebido em 10 de dezembro de 2020.

Avaliador A: 30 de março de 2021.

Avaliador B: 04 de maio de 2021.

Aceito em 26 de maio de 2021. 


\section{ABSTRACT}

This article analyzes the data collected over seven years of observation of ethnographic inspiration of community intervention practices in the public space of the center of Vitória, capital of the State of Espírito Santo. Going back to the recent history of the neighborhood, there is an emergence of new parameters for the normalization of the place that affect state interventions and community engagement in rehabilitation initiatives of the region. Focusing on the controversies about the definition of public problems in the neighborhood, we will seek to understand the limits to popular participation in a liberal political and economic context, the intensification of internal disputes among residents, over time, as well as the ineffectiveness of a management of space focused exclusively on the objective of making it a reality as a simulacrum of local history and culture, to the detriment of a lived neighborhood, where a plurality of common good ideals coexist.

Keywords: Government by Objectives, Guaranteed City, Liberal Grammar of Individual Interests, Public Problems, Community Associations.

\section{APRESENTAÇÃo}

Ao longo de sete anos de observação de inspiração etnográfica das práticas de intervenção no espaço público transcorridas na manch $^{2}$ de sociabilidade e lazer do Centro Histórico ${ }^{3}$ da cidade de Vitória, capital do Estado do Espírito Santo, identificamos uma profusão de vozes que disputam um imaginário de cidade e um modo de vida urbana territorializado. Assim vêm sendo mapeadas modalidades de se pensar e agir sobre a cidade, a partir desse bairro, mobilizadas por diferentes públicos em diferentes situações, através do Grupo de Pesquisa Diretório do CNPq Cidades, Espaços Públicos e Periferias ${ }^{4}$.

Nos deparamos em nosso espaço de observação com uma gestão que vê a cidade en-

\footnotetext{
2 Áreas contíguas do espaço urbano que se constituem como pontos de referência para a prática de determinadas atividades (MAGNANI, 1996). São dotadas de equipamentos e podem se conformar como regiões morais (PARK, 1979) simbolicamente delimitadas segundo modos de vida e comportamento. A mancha de sociabilidade do Centro Histórico de Vitória é melhor delimitada em Néspoli (2016).
}

3 Delimitação simbólica da região central do bairro, onde estão localizados os seus principais equipamentos culturais, incluindo os imóveis que compõem o patrimônio histórico da cidade e que serão objeto de projetos direcionados à sua valorização no circuito turístico nacional, vide Projeto Visitar, realizado em parceria entre a Prefeitura Municipal e o Instituto Goia de 2015 (INSTITUTO GOIA, 2015) .

4 Pesquisa financiada pelo EDITAL CNPq/FAPES No 22/2018 - PROGRAMA PRIMEIROS PROJETOS - PPP, número 058/2019. 
quanto um espaço referencial e informacional, administrado não em função da conciliação pelo diálogo com os desejos racionais dos seus habitantes (BREVIGLIERI, 2013), mas de acordo com processos de normalização que configuram “[...] o mundo em propriedades mensuráveis, implicando, por exemplo, no fato de que as propriedades dos humanos, das coisas e daquilo que lhes concernem sejam contempladas por um estado de regularidades previsíveis" (BREVIGLIERI, 2013, p. 218 a partir dos estudos de THÉVENOT, 1997).

Neste artigo, analisamos as controvérsias acerca da definição dos problemas públicos do bairro e os "[...] contornos nos quais as ações públicas oferecem uma pluralidade de envolvimentos possíveis e em que os atores buscam exprimir suas demandas e constituir justificativas legítimas" (MOTA, 2014, p. 41).

Assim, remontamos a modalidade de gestão do Centro de Vitória em sua história recente, refletindo sobre os efeitos do processo de expansão urbana da capital sobre a posição que o bairro ocupa na cidade atualmente. Partiremos, portanto, de uma contextualização do nosso espaço de observação para analisar a trajetória do bairro enquanto objeto de intervenção do poder público local e a sua relação com o modelo de gestão do espaço com o qual nos deparamos no início de 2014.

Identificamos a transformação do Centro, de região centralizadora de recursos infraestruturais de caráter macroeconômico a "bairro histórico", para onde são direcionados investimentos basicamente relacionados à restauração e à manutenção do patrimônio material, assim como destaca Waldetário (2009). As mesmas políticas urbanas que irão promover a efetivação da região enquanto área central (REIS, 2007) da cidade incidirão sobre a descentralização dos investimentos, dos órgãos públicos e de parte da população (incluindo as elites locais) para outras áreas da cidade. Após duas décadas de abandono ${ }^{6}$, observa-se, desde o final do século $\mathrm{XX}$, a emergência de novas formas de regulação do bairro que refletem nos processos globais que incidirão sobre centros históricos urbanos das cidades ocidentais de modo mais amplo. De núcleo urbano, o Centro passa a ser reconhecido como Centro Histórico, simulacro da autenticidade capixaba, berço cultural, representação simbólica de uma imagem da cidade que se pretende competidora no mercado mundial.

Breviglieri (2013, p. 224, tradução nossa) chama a atenção para o fato de que a concepção comercial da cidade incide na escala do indivíduo e na economia afetiva de natureza parti-

5 "le monde en propriétés mesurables, impliquant, par exemple, que les propriétés des humains, des choses et de leurs rapports, soit envisagées à l'état de régularités prédictibles".

6 Categoria nativa que estará presente também nas narrativas sobre o bairro que atravessam diferentes trabalhos acadêmicos desenvolvidos sobre o local (TRINDADE, 2015). 
cular, dado que "[...] as relações em público tendem a permanecer na superfície, a induzir uma 'neutralização' do sensível que limita o poder de estimulação da cidade" ${ }^{\text {”7 }}$ Essa ville garantie se erige e se sustenta através de uma proliferação de garantias a serviço do capitalismo contemporâneo e da ruína das promessas implícitas da metrópole cosmopolita:

A cidade garantida, assim como demonstrado anteriormente, não está comprometida com o incomensurável, que exigiria a reformulação da arquitetura de um mundo comum, em vez disso, ela se lança em um trabalho implacável de produção de indicadores de medidas e de sistemas de avaliação que se inscrevem em um movimento geral de normalização da metrópole cosmopolita $^{8}$ (BREVIGLIERI, 2013, p. 230, tradução nossa).

A emergência desse modelo de cidade está intrinsecamente relacionada, para Breviglieri (2013), com um modelo de governança característico ao capitalismo mundializado, um tipo de gestão da cidade que Thévenot (2015) chama de governança por objetivo.

Por um lado, o ambiente urbano é avaliado segundo parâmetros de atratividade, o que introduz critérios de julgamento que respondem a uma lógica consumista segundo a qual a atratividade do lugar não estará pautada pela afinidade ou dependência, ou por uma apropriação sensível (BREVIGLIERI, 2013). As modalidades de disputa que emergem nesse contexto serão atravessadas por uma gramática liberal dos interesses individuais, em oposição a uma gramática das grandezas plurais de bem comum (THÉVENOT, 2019). Caracteristicamente, os engajamentos individuais se assentam em uma disputa legítima, mas sem se referir diretamente a uma concepção substancial do bem comum e sim expressando uma escolha individual na forma de uma opção acessível à escolha de todos os outros indivíduos. Breviglieri (2013) caracteriza ainda o teor das garantias que tenderão a ser demandadas: elas se deslocam das questões próprias a uma arquitetura dos usos em favor da elaboração de um plano defensivo, visando a neutralização dos conflitos inerentes à vida em comum.

Em um segundo momento, avaliamos neste artigo como essa concepção mercantil de cidade será ressignificada, no plano micro, pelos atores engajados em projetos de requalificação da região. Os mesmos critérios de atratividade efetivados ao longo do tempo, e que caracteriza-

\footnotetext{
7 "Les relations en public tendent à rester en surface, à induire une «neutralisation» du sensible qui limite le pouvoir de stimulation de la ville".

8 'La ville garantie, nous l'avons dit, n'affronte pas l'incommensurable qui appellerait à refonder l'architecture d'un monde commun, et se jette plutôt dans un travail acharné de production d'indicateurs de mesures et de systèmes d'évaluation pour garantir la qualité de ses projets d'édification qui s'inscrivent dans un mouvement général de normalisation de la métropole cosmopolite".
} 
rão os processos governamentais de estandardização do território, fundamentarão os objetivos por trás das ações comunitárias em movimento. Deste modo, o bem comum que atravessa as diferentes propostas de atuação sobre o espaço (tanto aquelas empreendidas pelo poder público quanto pelas iniciativas dos moradores) é a requalificação urbana do bairro. Destacaram-se, nos primeiros anos de trabalho de campo, os embates entre a Associação de Moradores do Centro de Vitória (Amacentro) e o poder público, que giram em torno das ações necessárias para a realização satisfatória desse projeto amplo de requalificação, tendo a cultura como recurso político de inserção do bairro em uma agenda política local.

Apesar de atuante, a Associação apresenta dificuldades em traduzir suas reivindicações em princípios gerais capazes de transcender os limites do bairro e atrair o investimento necessário à sua satisfatória requalificação. Entendemos que essas iniciativas serão limitadas por uma forma de civilidade liberal (THÉVENOT, 2008) que se legitima através da promoção de espaços de participação (os Conselhos Deliberativos, no caso) que, na prática, são meros “espaços de opiniões” na escala do projeto, não pretendendo nem especificar nem mesmo contribuir abertamente para a realização do bem comum. Ao longo do tempo, essas insatisfações fomentaram disputas locais que culminaram na conformação de dois públicos oponentes e que demandam por um conjunto de bens fundamentais inconciliáveis entre si.

Finalmente, demonstramos os efeitos do princípio de uma cidade garantida nos termos de Breviglieri (2013) sobre a configuração de uma gramática liberal de engajamento (CHEYNS; THÉVENOT, 2019; THÉVENOT, 2019). Localmente, há lacunas nesse modelo de gestão denunciadas pelos próprios atores sociais e coletivos interventores nesse espaço, que impõem limites à sua atuação e produzem distorções, tornando os recursos mobilizados a favor da requalificação do bairro também uma fonte de transtornos. As ações situadas espacialmente, carentes de um suporte estatal efetivo em caráter mais abrangente, se tornarão fonte de descontentamento por parte dos moradores do bairro, sendo percebidas, por um público emergente, como causadoras de problemas (em certa medida, os mesmos problemas que visam combater).

\section{DE BAIRRO A SIMULACRO DA IDENTIDADE LOCAL}

A região central da capital foi o núcleo primário de ocupação do solo da cidade de Vitória. Ao longo de toda a trajetória de desenvolvimento e expansão da cidade, atraiu o maior fluxo de investimentos públicos e privados no local, situação que se reformula apenas a partir do 
século XX, quando é implementado o projeto de expansão urbana da cidade (MENDONÇA et $a l ., 2009)$. A região, até os dias de hoje compreendida de forma muito mais ampla no imaginário social local do que na delimitação administrativa do bairro que leva o seu nome, constituiu, ao longo de boa parte da história da cidade, a única zona de ocupação urbanizada da capital, já o bairro Centro irá centralizar a oferta de serviços e o endereço da parcela mais abastada da sua população até esse período.

As mesmas obras, concluídas na década de 1970, que contribuíram para a consolidação do bairro como Área Central ${ }^{9}$ da capital, estimularão a formação de novas áreas ou subáreas centrais na cidade, bem como o seu processo de metropolização. O aterro da Esplanada da Capixaba e a finalização das obras do Porto de Vitória, situados no bairro, simbolizam a consolidação de um projeto de maximização do uso do solo do Centro, com obras que abriram quarteirões inteiramente voltados para uma ocupação vertical do território, bem como a construção e ampliação de avenidas que são, ainda na atualidade, algumas das principais artérias rodoviárias da cidade (CAMPOS JÚNIOR, 2002; GOMES, 2008).

O mesmo projeto consolida a descentralização dos investimentos infraestruturais, por parte do poder público municipal e estadual, em favor das áreas de expansão da capital ou de sua região metropolitana (CAMPOS JÚNIOR, 2002). São inauguradas, em 1979 e 1989 duas novas pontes conectando a capital e a cidade de Vila Velha, bem como é reformada a Ponte da Passagem, que conecta a ilha a sua região continental (CAMPOS, 2016), compondo o que hoje conforma o eixo economicamente mais dinâmico da cidade.

Se intensifica assim um processo de migração intramunicipa $1^{10}$ das elites que incide sobre a composição populacional do Centro. Órgãos públicos são realocados, atraindo para o seu novo entorno as sedes das principais empresas privadas atuantes no Estado, assim como os escritórios de profissionais autônomos e prestadores de serviços, provocando o progressivo esvaziamento de imóveis públicos e comerciais localizados no bairro (TRINDADE, 2015).

A chamada 'degradação' ou crise da Área Central, enquanto fenômeno que se generalizou em cidades de várias partes do mundo está intrinsecamente

\footnotetext{
9 Conceito aplicado por Reis (2007) para caracterizar a região que concentra o comércio e os serviços mais especializados para a população de toda a aglomeração urbana da Grande Vitória, bem como a população de mais alta renda da cidade, aglutinando praticamente todas as atividades comerciais, serviços, sede das repartições e instituições públicas municipais, estaduais e federais, além das opções de lazer e diversão da cidade.

10 As migrações intermunicipais e interestaduais são igualmente intensificadas nesse período, com a atração de um grande contingente populacional para o território que hoje compõe a Região Metropolitana da Grande Vitória, processos relevantes para a reconfiguração urbana da cidade e que incidirão sobre o processo de "favelização" da capital.
} 
associada com a tendência à descentralização das atividades terciárias na metrópole capitalista, manifestando-se mais notadamente a partir da segunda metade do século XX (REIS, 2007, p. 103).

Apenas na década de 90 o Centro volta a tornar-se interesse específico do poder público. O que se destaca nesse período é a mudança do teor dos investimentos e a forma como o bairro passa a ser regulado a partir deles. As intervenções urbanísticas no Centro de Vitória que, até a década de 1970, buscaram a higienização, o embelezamento e a modernização da cidade a partir do bairro, serão, nas duas décadas seguintes, substituídas por ações preservacionistas que, segundo Waldetário (2009, p. 57), “[...] coincidem com o período de estagnação do desenvolvimento local e com a impregnação dos aspectos de abandono e degradação”. O Centro passa a ser valorizado pelo valor simbólico que é capaz de atribuir à própria cidade (NÉSPOLI; BLANC, 2016).

O bairro será então o espaço simbólico de implementação de um novo modelo de cidade em consonância com as tendências internacionais de planejamento urbano: se tornará objeto de intervenções que tem como estratégia o melhoramento na qualidade de vida e a valorização do patrimônio histórico. A participação popular, através da criação de instâncias de deliberação participativas, é outra característica que marcará esse novo modelo de gestão do espaço, como demonstra Botelho (2005).

Uma série de projetos são implementados na região a partir desse período, todos eles voltados para uma requalificação do lugar a partir do seu patrimônio material e o valor imaterial que lhe é correlato, servindo à efetivação de uma imagem de cidade: o seu berço histórico e cultural, critérios de valor agregados ao coeficiente de autenticidade das cidades contemporâneas do qual nos fala Breviglieri (2013).

A reforma, restauração e manutenção dos monumentos históricos ali localizados, bem como a promoção de um projeto de incentivo ao turismo no local são implementados com o intuito de promover a retomada de funções e significados do bairro para a população capixaba (WALDETÁRIO, 2009). Assim como o processo que levou à instalação de placas de trânsito sinalizando o "Centro Histórico" em pontos próximos ao núcleo originário do bairro, se consolida, a partir desse período, uma nova "vocação" e será esse o referencial a partir do qual o bairro será tratado, sobretudo, mas não exclusivamente, pelo poder público nos anos seguintes.

O Centro, mais do que um bairro, passa a ser governado enquanto patrimônio histórico e cultural que deve agregar valor de mercado à capital como um todo. Esse objetivo irá inspirar iniciativas de intervenção sobre equipamentos culturais, vias de circulação e mesmo iniciativas de controle dos usos dos seus espaços, se efetivando através da formalização de instâncias de 
deliberação participativas.

Para Breviglieri (2013), a gestão participativa é demonstrativa da operação do liberalismo econômico no plano da pacificação das violências humanas (ou o seu equivalente no liberalismo político), garantindo a efetivação das ações governamentais sob um suposto compartilhamento das decisões, quando, na prática, o seu funcionamento é meramente formal. Essa concepção comercial da cidade irá incidir, na escala do indivíduo, sobre uma economia afetiva de natureza particular, introduzindo critérios de julgamento que respondem à uma lógica consumista: "A atratividade da cidade se define, portanto, sobre o caminho da sua legitimação mercantil, em uma exacerbação de uma competição que as opõe"11 (BREVIGLIERI, 2013, p. 219, tradução nossa), referenciais que correspondem ao modelo de city marketing apontado por Botelho (2005) como inspiração para os projetos designados para a região nesse período.

Por outro lado, a conformação da arena pública de disputa pela definição dos problemas do Centro aponta para a complexidade do contexto, até mesmo no que se refere à definição de qual é o patrimônio (histórico/cultural) do bairro e como deve ser tratado.

Observa-se, em consonância com os estudos de Cheyns e Thévenot (2019), que a gestão governamental do bairro está fundada sobre a operacionalidade do objetivo de consagrar ao bairro o papel de simulacro da história local, se isentando da especificação do bem comum dos seus moradores ou sequer contribuindo abertamente para a sua realização. Em nível municipal, as ações limitam-se a estabelecer critérios de regulação, como aqueles que dizem respeito especificamente à ocupação do território e à proteção da paisagem.

A revisão do Plano Diretor da Cidade de Vitória, em 2018, persiste em conferir destaque ao bairro com iniciativas que visam a promoção da sua revitalização basicamente através da flexibilização dos parâmetros de regulação do uso do solo com medidas que visam a atração de investimentos privados para a região (VITÓRIA, 2020). Localmente, a elaboração desses documentos terá como desafio a promoção da participação da sociedade civil, condicionante estbelecido nacionalmente pelo estatuto das cidades. Fernanda ${ }^{12}$ destaca a baixa efetividade desses espaços: "pouco participativo, pouco democrático o ambiente, sabe?". A arquiteta, que ocupou cargo na Coordenação de Revitalização Urbana da Prefeitura Municipal de Vitória, exemplifica assim como o caráter deliberativo dos processos de regulação e normatização da política urbana servirão exclusivamente como via de efetivação dos próprios parâmetros de regulação do território, não como espaço de publicização de problemas ou proposição de possíveis resoluções.

11 “L'attractivité des villes se définit donc sur le chemin de leur légitimation marchande, dans une situation d'exacerbation d'une compétition qui les oppose".

12 Os nomes de todos os nossos interlocutores de pesquisa foram aqui alterados para garantir o seu anonimato. 
No plano micro, as estratégias articuladas por novos e antigos investidores da região se apropriarão da lógica discursiva, dos modos de fazer e até mesmo da estética que emerge nesse processo de estandardização da cidade através do bairro. Dessa maneira, observamos processos de constituição e dissolução de diferentes públicos engajados em ações interventivas em torno de um objetivo comum: a "requalificação do Centro".

Observamos durante a pesquisa que a expressão revitalização urbana/cultural presente até os dias atuais nos documentos e nos discursos estatais sobre o bairro vem sendo progressivamente problematizada pelos nossos interlocutores, sendo substituída em suas falas por diferentes expressões, todas atravessadas pela ideia de requalificação do espaço. Reavivamento foi a categoria acionada por Carolina ${ }^{13}$ em uma das nossas conversas informais, bem como em sua entrevista. A categoria Revitalização ainda está presente no discurso de Stella ${ }^{14}$, mas acompanhada da seguinte reflexão: "revitalizar o que? O centro nunca morreu".

A coexistência de categorias nativas nesse espaço de observação não é neutra, pois sinaliza para diferentes definições dos sentidos atribuídos aos processos de transformação desejados e que dizem respeito aos problemas definidos pelos públicos engajados em iniciativas de intervenção no espaço e às soluções apontadas. A noção de requalificação é aqui utilizada sempre em referência aos engajamentos dos atores como uma categoria analítica que emerge dos dados, um esforço para sintetizar o que seria um objetivo comum que atravessa uma pluralidade de discursos. Por revitalização são compreendidas as ações estatais que seguem a regulamentação da região nos documentos oficiais.

\section{O AGIR EM COMUM EM UM CONTEXTO POLÍTICO LIBERAL}

No início de 2014, um conjunto relativamente fragmentado de atores individuais ou coletivos buscava coordenar as suas ações em função da realização de diferentes iniciativas de intervenção sobre o bairro, iniciativas essas claramente identificadas com aquelas colocadas em movimento pelo poder público nos anos anteriores: a defesa e a valorização de um Centro Histórico e cultural atravessavam as suas estratégias de atuação.

Intervindo diretamente sobre o bairro, esses atores individuais ou coletivos promovem

13 Presidente de uma associação cultural atuante no território.

14 Empreendedora cultural local e ativista, atualmente membro da Amacentro. 
os usos dos seus espaços públicos (expressando a sua "vitalidade cultural") e a sua manutenção (com vias a "requalificar" o espaço vivido). Identificamos campanhas de conscientização quanto aos problemas do bairro, de promoção da leitura, de criação de hortas comunitárias em pontos viciados de lixo ${ }^{15}$, como projetos coletivos dos moradores; além da promoção de eventos culturais de menor ou maior expressão, iniciativa de grupos de empreendedores culturais da região. Entre o surgimento do Samba da Xepa (em 2010) e a realização do Alto de Natal (a partir de 2018), diversos eventos culturais e de lazer passaram a compor o calendário do bairro, alguns inicialmente motivados pela integração da comunidade, e se tornaram referência entre os festejos da capital, como o Carnaval de rua.

Essas iniciativas, conformadas através de associações de proximidade (CEFAÏ, 2011), contribuirão para a constituição de públicos em torno de problemas do bairro, os próprios eventos por eles organizados servindo como espaços de definição e, posteriormente, publicização dos seus problemas. Se conformarão igualmente comunidades em rede (BOLTANSKI; CHIAPELLO, 2009) entre empreendedores culturais locais, bem como serão ampliadas as redes de inter-relação em escala local, potencializando o potencial de mobilização pública desses atores e a sua reação às situações problemáticas ${ }^{16}$ envolvendo o bairro e a sua gestão.

Distintas ações do poder público local foram denunciadas por nossos interlocutores como medidas limitadoras de um processo de dinamização cultural do Centro, tais como a aplicação de multas a estabelecimentos promotores de eventos culturais e outras formas de controle que, segundo eles, estariam levando à falência alguns estabelecimentos culturais da região.

Nos idos de 2015, correram rumores (GLUCKMAN, 1963) de que o Projeto de Lei Municipal 16/2015 que propunha o fechamento dos bares a partir das 2 horas da manhã em toda a cidade (GAZETA ONLINE, 2015) seria reformulado, dada a sua baixa adesão, para uma proposta de implementação da medida na região do Centro da cidade, com vias a reduzir a circulação de pessoas (o que fora entendido por seus proponentes como medida de segurança pública). Já em 2017, uma medida do Ministério Público do Espírito Santo (MP-ES) torna esses rumores

15 Categoria já apropriada e presente no discurso dos nossos interlocutores, em caráter de denúncia aos próprios moradores (dado o descarte inadequado do lixo) ou ao poder público (dada a inefetiva manutenção dos espaços públicos do bairro e/ou fiscalização dos seus usos): "Então a gente dá um jeito!" (Maria, uma das fundadoras da horta urbana Quintal da Cidade, projeto que se mantém com recursos próprios e participação comunitária).

16 Os momentos críticos, ou situações problemáticas, são aqui definidos como contextos nos quais "os múltiplos processos de organização coletiva e de organização pessoal, mediados por instituições sociais, já não estão em sintonia" e, diante do entendimento de que as tensões e conflitos experimentados não são passíveis de nova acomodação, "pessoas, grupos, organizações e instituições se mobilizam, em lugares e momentos diversos, e tentam reconhecer, cada um a partir de sua perspectiva, em que consiste esse distúrbio e, se necessário, tentam identificá-lo e defini-lo, atribuir-lhe causas e razões, determiná-lo como um problema" (CEFAÏ, 2017, p. 189). 
um fato, impondo o recolhimento das mesas dos bares no Centro Histórico a partir das 23 horas, o que será objeto de grande mobilização popular: “[...] as pessoas organizaram dois eventos: um foi o ‘cadeiraço da Ubaldo', que é aquela praça que tem o homem do martelo, e o outro foi o 'Enterro da Rua Sete"' (Carla, ativista cultural do bairro). Carla se refere ao movimento de ocupação a Rua Viva pelos moradores do bairro, com suas próprias cadeiras (GAZETA ONLINE, 2017), e a encenação de um cortejo fúnebre pela "morte da Rua Viva", com um dos célebres sambistas locais sendo arrastado dentro de um caixão, seguido por sua viúva $(G 1,2017)$.

No mesmo ano é promovido o Abraçaço do Mercado da Capixaba, “[...] ato público em defesa da restauração do Mercado da Capixaba e dos patrimônios abandonados no Centro Histórico de Vitória" (AMACENTRO, 2020, on-line). Trata-se de um evento promovido pela Associação de Moradores do Centro de Vitória (Amacentro) e que coloca à prova o projeto de restauro em andamento pela prefeitura. $\mathrm{O}$ grupo, que se mantém atuante, denunciava àquela época a falta de participação popular ou as condições de participação garantidas pelos processos deliberativos estatais.

Por outro lado, o poder público segue sendo acusado de produzir os transtornos que provocam os conflitos no âmbito do bairro, em decorrência dos eventos promovidos no local ${ }^{17}$ : a oferta insuficiente de banheiros químicos (ou públicos), a baixa efetividade do policiamento, a negligência em controlar a emissão inadequada de ruídos ou a falta de planejamento logístico para o reordenamento satisfatório das vias públicas, alguns dos principais focos de conflito entre os defensores das iniciativas culturais em movimento e os moradores que a elas se opõem. Mas a própria modalidade de gestão do bairro será colocada à prova, devido à incapacidade do poder público agir como um operador de bens públicos e de suas instâncias de participação popular servirem como catalizadores de uma pluralidade de bens fundamentais:

Então, antes de mais nada, a gente está situado em um lugar absolutamente
histórico que precisa ser valorizado. Mas esse projeto então começou numa
conversa a respeito da necessidade de se requalificar aquela região. A gente
tinha um momento ali de lixo acumulado, uma violência gritante, o uso aberto
de crack no entorno, a prostituição, tudo isso que acontece nos grandes centros
urbanos em estado de degradação. (Aline, presidente do Instituto Quorum em
discurso na Câmara Municipal de Vitória).

Localmente, os investimentos públicos urbanos direcionados à região até meados do sé-

17 Pelo próprio poder público estadual (como o Viradão), pela iniciativa local (como as feiras, rodas de samba e demais eventos promovidos em espaços públicos do bairro) ou pela iniciativa público-privada (como o festival de Cinema, entre outros). 
culo XX promoveram modificações significativas na morfologia do bairro. A expansão do Porto de Vitória envolveu um complexo de obras infraestruturais, o aterro de parte da orla e consequente expansão do território, com a abertura da Esplanada Capixaba (CAMPOS JÚNIOR; 2002; GOMES, 2008). Ao mesmo tempo que são criados quarteirões inteiros e é estimulado o processo de verticalização da região como um todo, em função da maximização dos lucros com o uso do solo, ocorrem os processos de migração interna. Muitos edifícios que serviram como sede de órgãos públicos, hotéis, prédios comerciais e residenciais foram esvaziados a partir de então e permanecem abandonados na região, apresentando riscos para a população.

Em 2017, com o objetivo de dar visibilidade para os efeitos desse processo e cobrar ações do poder público, a própria Amacentro empreendeu um levantamento dos imóveis abandonados no Centro, em uma campanha para pressionar ações para fiscalizar a manutenção desses imóveis e restituir a sua função social: “[...] esses prédios vazios podem ter uma ocupação habitacional ou comercial, só que pelo esvaziamento de pessoas a gente tende a pedir programas habitacionais para o centro de Vitória" (Emerson, ex-presidente da Associação) ${ }^{18}$. Mais do que denunciar, esses atores irão intervir diretamente no enfrentamento dessas questões.

Pouco depois de realizado o levantamento dos imóveis em desuso, em maio de 2017, 40 famílias do Movimento Nacional de Luta pela Moradia (MNLM) ocupam o antigo prédio do Instituto de Aposentadorias e Pensões dos Industriais (IAPI), localizado nas imediações da Praça Costa Pereira, ao lado do Teatro Carlos Gomes, um dos principais cartões-postais da cidade e núcleo simbólico do Centro Histórico de Vitória.

A Superintendência do Patrimônio da União no Espírito Santo (SPU-ES), que responde pelo controle do imóvel, logo se posicionou contrária a ocupação do prédio, conquistando a reintegração da posse, por vias judiciais, em julho do mesmo ano. Diante da pressão popular, a Defensoria Pública da União e a Defensoria Pública do Estado do Espírito Santo (DPE) determinaram a intimação do município de Vitória, na pessoa do prefeito Luciano Rezende, para que fosse realizado o cadastramento social das pessoas que ocupavam o edifício para " [...] verifica-

18 Essas denúncias se intensificaram durante os últimos anos e contam com o apoio de diferentes iniciativas acadêmicas em projetos de extensão que tratam o problema, buscando conscientizar a população, discutir possíveis soluções e propor formas de intervenção à iniciativa pública e privada. O cortejo promovido ao longo da Campanha pela Função Social da Propriedade, em 2019, exemplifica os modos como esses atores articulam seus múltiplos pertencimentos nas ações políticas comunitárias, ampliando suas redes de inter-relação locais e mobilizando os diferentes recursos políticos adquiridos ao longo do tempo. Fora então realizado um percurso, entre diferentes imóveis em desuso do bairro, ao longo do qual informações técnicas davam vida para prédios históricos que compõem o conjunto patrimonial negligenciado e relatos de moradores rememoravam as antigas funcionalidades dos imóveis comerciais em deterioração, tudo em forma de intervenção artística, atraindo os passantes e traduzindo em poemas as diferentes dimensões do problema. 
ção de futuros encaminhamentos em programas habitacionais ou assistenciais" (DEFENSORIA PÚBLICA DA UNIÃO, 2020). O juiz responsável ordenou a criação de uma comissão composta por representantes da DPU, DPE, Ministério Público Federal e os réus na ACP, ou seja, União, Estado e município de Vitória, para efetivar a medida liminar que determinou prazo de seis meses para adoção de iniciativas e políticas públicas para garantir o direito à moradia às famílias que ocupavam o edifício Presidente Vargas (localmente conhecido como "antigo prédio do IAPI"). Segundo os representantes do SPU-ES, em entrevista ao jornal A Tribuna Online, o imóvel seria destinado a um programa de habitação popular (TRIBUNA ONLINE, 2017), o que, até o início do ano de 2021, ainda não aconteceu.

A forma como a Associação atuará nesse caso, desde a publicização das informações recolhidas sobre os imóveis em desuso até as ações de conscientização na comunidade, sinalizam para as estratégias utilizadas pelo grupo, que visam conciliar as ações realizadas e os pontos de vista divergentes entre moradores quanto à questão:

De forma direta, a gente não apareceu, porque a gente sabia que teria, dentro do bairro do Centro, as pessoas que são mais antigas, conservadoras, que tem um olhar diferenciado para esses processos de reivindicação que acontecem, de uma forma conservadora... preconceituosa, né? Então, para preservar as nossas condições políticas, pra continuar sendo representante... [...] a gente faz esse processo de articulação e dá condições de permanência para eles, debatendo com os moradores sobre os aspectos que tem... "oh! São imóveis vazios, esses imóveis estão trazendo insegurança, tá dando pombo... eles tão ali ocupando, e estão fazendo o trabalho de pressionar o poder público para ter habitação. Nós queremos habitação também ali. Então eles estão cumprindo o papel que a gente também quer que aconteça"... (Emerson, ex presidente da Amacentro, grifo nosso).

O potencial da Amacentro em tornar público o problema dos imóveis em desuso no bairro e o apoio informal oferecido por membros da sua diretoria em ocasião da ocupação conferirá destaque para a Associação enquanto ator político opositor à gestão pública municipal em vigor, mas também será vetor da intensificação dos conflitos internos, no âmbito do bairro, que tornarão a definição dos seus problemas e das soluções que lhes dizem respeito, objeto de questionamento entre um grupo à princípio fragmentado de moradores.

Entre os problemas tornados públicos pelo nosso conjunto de interlocutores e a pluralidade de bens fundamentais demandados pelos moradores do bairro, há ainda dissonâncias no que se refere à definição dos meios para a realização satisfatória dos fins.

No plano da gestão urbana, os objetivos se restringem ao cumprimento dos parâmetros de normatização do espaço urbano. Centrando o valor do bairro no patrimônio material locali- 
zado na região, esta área deixa de ser percebida como uma área habitada, plural e complexa. "A condição urbana, que se baseia na pluralidade assumida e na complexidade das coisas humanas ${ }^{19}$ " (BREVIGLIERI, 2013, p. 228, tradução nossa) é alheia ao acervo patrimonial, histórico e imagético que confere centralidade ao bairro como objeto de intervenção do poder público municipal. Assim, os males comuns a experiência de viver na cidade, apesar de conhecidos, não compõem o rol dos problemas a serem enfrentados, não são reconhecidos como bem público ou objeto de intervenção do estado.

Interessa-nos analisar os modos como esse modelo de gestão da coisa pública ou, nesse caso, do espaço público do bairro, incide ao longo do tempo sobre os engajamentos dos atores e as disputas internas ao conjunto de moradores do bairro em torno da definição dos seus problemas e sua devida resolução.

\section{O QUE GARANTE A CIDADE?}

Desde os anos iniciais de pesquisa, observamos que os relatos dos conflitos entre os próprios moradores apontam para uma dissonância entre os defensores da dinamização cultural da região como recurso político de visibilização dos seus problemas e um conjunto ainda fragmentado de críticos dos eventos decorridos no bairro, devido aos inconvenientes a eles correlatos. Até então ações individuais tornavam públicos tais descontentamentos, como na ocasião em que um morador jogou água da janela do seu apartamento ou quando outro deu tiros pro alto, sempre com vias a dispersar os frequentadores dos eventos, até denúncias ao Ministério Público Estadual solicitando a proibição da realização de atividades regulares decorridas no bairro ${ }^{20}$.

O ano de 2018, período de eleições presidenciais, se inicia no Centro de Vitória com intensa mobilização em torno da disputa pela Diretoria da Associação de Moradores. Por um lado, a chapa articulada à diretoria em exercício defende a manutenção dos equipamentos urbanos em função da utilização dos espaços públicos do bairro a partir de iniciativas culturais e de lazer, muitas das quais apoiadas diretamente pela Associação ou promovidas por ela na gestão em exercício. Por outro lado, a chapa da oposição defende um tratamento ordenado desses espa-

19 "la condition urbaine, qui repose sur une pluralite assumee et sur la complexification des affaires humaines".

20 Segundo os rumores, uma dessas denúncias motivou a tentativa de implementação da medida que visava tornar obrigatório o recolhimento das cadeiras dos bares após determinado horário. 
ços, através do controle dos usos e ruídos, circulação e acesso, pelo próprio poder público e via policiamento militar. Enquanto a dinamização cultural do centro segue sendo o meio proposto pelo primeiro grupo para dar visibilidade aos males do bairro e potencializar a mobilização pela sua resolução, a intervenção do poder público, sobretudo em ações de segurança e restrição das atividades que nele ocorrem, é a base da proposta do segundo. Esse pleito será aqui analisado como um momento crítico ${ }^{21}$ que marca a polarização de dois públicos e a formação de uma instância de representação alternativa para os moradores.

Esse público emergente desqualificará as ações empreendidas no bairro pelos movimentos atuantes e interventores sobre o espaço, deslocando o problema, da relação com o poder público e a ausência de investimentos infraestruturais, para a relação entre os próprios moradores e usuários do bairro ditos imorais e, portanto, indesejáveis.

É importante destacar que interesses comuns, já que visam a melhoria da qualidade de vida no bairro, se polarizam, acirrando uma disputa interna com potencial de desmobilização da própria comunidade, mas que remetem também aos conflitos que transcorrem em um plano mais amplo, entre a Associação e o poder público municipal, mais especificamente, e entre o associativismo comunitário e a conjuntura política nacional. Tais disputas conferem destaque, finalmente, para a insuficiência de um modelo de urbanidade.

Breviglieri (2013, p. 224, tradução nossa) destaca a necessidade de reconhecer o horizonte político e moral que envolve o esboço de uma experiência humana em meio urbano pautada em modalidades de conduta pública assentadas no princípio da indiferença civil, como no contexto das cidades cosmopolitas. No plano prático, a governança liberal se dá através da "[...] neutralização significativa de seus espaços por meio de sua redução programada a um estado de qualidade padronizado organizado por um circuito de informação a serviço dos atores da cidade (moradores e empresários)" ${ }^{22}$, tendo como exemplo o controle das práticas que escapam à clara bipolarização entre público e privado. Esse modelo de gestão do espaço público urbano se assenta na tentativa de desqualificação de características que lhe são inerentes.

Reconhecendo que o espaço público não vive senão na medida em que contém um

21 Os momentos críticos, ou situações problemáticas, são definidos aqui como contextos nos quais “[...] os múltiplos processos de organização coletiva e de organização pessoal, mediados por instituições sociais, já não estão em sintonia" e, diante do entendimento de que as tensões e conflitos experimentados não são passíveis de nova acomodação, “[...] pessoas, grupos, organizações e instituições se mobilizam, em lugares e momentos diversos, e tentam reconhecer, cada um a partir de sua perspectiva, em que consiste esse distúrbio e, se necessário, tentam identificá-lo e defini-lo, atribuir-lhe causas e razões, determiná-lo como um problema" (CEFAÏ, 2017, p. 189).

22 “neutralisation sensible de ses espaces à travers leur réduction programmée à l'état de qualité normalisée agencé pour un circuit informationnel au service des acteurs de la ville (citadins et entrepreneurs)". 
conjunto de produções sensíveis que geram uma densidade experiencial, o autor destaca que toda originalidade, toda diferença, todo conflito, toda inconveniência, todo desejo contrariado e suscetível de emergir nesse contexto, e que lhe concedem sua verdadeira corporeidade especializada, tendem a ser objeto de controle e repressão segundo uma civilidade liberal.

É necessário colocar em questão o caráter cosmopolita da cidade de Vitória. Não vimos aqui os efeitos esperados de uma modalidade de gestão que pretende a inserção da cidade em um circuito turístico internacional ${ }^{23}$ e o aprimoramento do potencial atrativo da região para grandes investimentos. Ao contrário, ocorre um processo ambíguo em "[...] que ao discurso da globalização e da reestruturação urbana associa-se o do atendimento de demandas locais [...], em uma tentativa de inventar tradições e reafirmar a antiga centralidade" (BOTELHO, 2005, p. 69). Porém, observamos como esse modelo de gestão, claramente identificado com o liberalismo econômico, se expressa em um liberalismo político, por mais que, no plano micro, ele possa se desenvolver de forma paradoxal.

Em nosso contexto de observação, as propostas de gestão do bairro defendidas pelas chapas em disputa pela diretoria da Amacentro assumem publicamente percepções sobre os seus espaços públicos (e a composição da população que nele circula), seus usos e sentidos e o Samba da Xepa ${ }^{24}$ é vetor simbólico dos conflitos que antecedem esse contexto eleitoral e a conformação dos dois grupos que irão concorrer pela representação dos moradores.

Já considerado um evento tradicional de samba local, a roda de samba acontece aos sábados e se estende por toda a tarde. Quando iniciamos o trabalho de campo no Centro, o evento era realizado em frente a um bar, a própria roda de samba ocupando uma lateral da rua, com as mesas e cadeiras dos frequentadores espalhadas por uma faixa de aproximadamente 20 metros, de um lado e de outro de uma via pública que permanecia aberta, com baixo fluxo de veículos. Essa área do bairro se configura como um dos muitos pontos da região marcados pela presença de edifícios multifuncionais, nos quais há estabelecimentos comerciais no primeiro

\footnotetext{
23 A título de exemplo, o aeroporto de Vitória oferece exclusivamente opções de voos nacionais, ainda restritas e instáveis. As ofertas durante a semana incluem São Paulo, Rio de Janeiro, Belo Horizonte, Brasília e Salvador (GOVERNO DO ESTADO DO ESPÍRITO SANTO, 2020) e, ao longo da temporada de verão 2020, foram lançadas opções semanais em direção a Governador Valadares, Ilhéus, Porto Seguro e Salvador (GAZETA ONLINE, 2020).

24 O evento é atualmente também conhecido como Samba da Rua 7 ou Samba do Nei. Segundo relatos, a roda de samba fora criada em 2010 e acontecia no calçadão da Rua Viva, bem ao lado das barracas de feira. Um grupo de puxadores dava início à roda, aberta aos possíveis demais interessados. Posteriormente, o grupo se instalou mais próximo de um dos bares localizados no início da rua. Diante do sucesso do evento, os donos dos bares passaram a disputar a fixação territorial da roda. Atualmente, a roda acontece no Bar do Nei, os músicos permanecem dentro do bar, contam com caixas de som e microfones.
} 
pavimento e imóveis residenciais nos demais andares. Os conflitos entre alguns dos moradores dessa área e os promotores do evento exemplificam as disputas de mesma ordem fragmentadas em diferentes locais da região e que remetem a algumas das inconveniências provocadas pelos atravessamentos entre público e privado, intoleráveis no âmbito de uma civilidade liberal, como demonstra Breviglieri (2013).

Nesse caso exemplar entre os possíveis, em determinado momento, mais do que acionar o Disque Silêncio ou protocolar denúncias na prefeitura, alguns dos moradores de um prédio vizinho se organizaram para suspender a realização do samba, o tratamento da questão se tornando ponto em discussão na disputa pela gestão do próprio condomínio. Insatisfeitos com os desdobramentos do caso $^{25}$, esses moradores começam a articular novas estratégias e composições, dentre elas a formação de uma chapa para concorrer à diretoria da Associação de Moradores do Centro de Vitória.

Se tomarmos o Samba da $\mathrm{Xepa}^{26}$ como divisor simbólico dos grupos em oposição no processo eleitoral pela diretoria da Amacentro, em 2018, notaremos que alguns dos seus fundadores e apoiadores compõem ou apoiam a Chapa 1, enquanto a Chapa 2 será formada por alguns dos seus denunciantes, incluindo parte dos moradores do referido edifício. Mais do que o samba, o que é colocado em disputa entre as diretorias inscritas são duas vivências de bairro, diretamente relacionadas a percepções sobre o acesso e uso dos seus espaços públicos.

Ao mesmo tempo, assim como é reportado em jornal local (SÉCULO DIÁRIO, 2018), é o próprio instrumento político, a Associação, que é objeto de disputa, de um lado, por uma chapa vinculada ao poder público municipal (ao seu ex-presidente e então vereador) e, do outro, por um grupo independente de moradores que persiste em defender publicamente a autonomia de gestão da instância de representação (e vinculado a diretoria em exercício). Esses grupos são derivados daqueles que lhes antecederam na sucessão da diretoria da Amacentro, mas se apresentam nesse momento reconfigurados, seja no que se refere à sua composição ou à sua própria definição e, portanto, a definição dos seus problemas.

É através dos múltiplos momentos de disputa entre atores individuais ou coletivos que a arena pública em torno dos problemas do Centro de Vitória vai assumindo sua conformação atual. De acordo com Cefaï (2011, p. 5): "Essas situações tomam a forma de provas de alerta,

25 Que se encaixa perfeitamente na situação mencionada por Emerson quanto à demanda de "segurança pública" recebida pela associação ao longo da sua gestão.

26 É importante destacar que o samba é veículo de mobilização popular recorrentemente acionado nesse contexto, servindo também como ferramenta política de protesto acionada por esses atores coletivos locais. Ainda em 2016, foi realizada uma roda de samba na Rua Sete em protesto às represálias e políticas que tentavam "[...] inibir as tradicionais manifestações populares no bairro" (G1, 2016, on-line). 
de experimentação, de medida, de testemunho de negociação, de estratégia, de conversação, de deliberação...". As motivações e objetivos, a unidade e a identidade que se consolidam em chapas concorrentes à diretoria da Amacentro, em 2018, são produto do processo prático de enfrentamento entre próprios grupos: públicos em processo de conformação e os problemas a partir deles definidos.

Assim também, o processo de qualificação dos bens desejados, inicialmente por atores individuais e como bens privados (o incômodo com o barulho, o cheiro de urina na calçada após as festas, a insegurança com relação à presença de pedintes ou "moradores de rua"), são enfim expressos em bens públicos (a questão da ordem urbana, a questão da segurança pública, a questão dos moradores ou usuários indesejados, dentre outras).

As assembleias de moradores foram, desde o início do nosso trabalho de campo, espaços de exposição dos descontentamentos dos moradores, mas o diálogo entre a diretoria em exercício e um dos participantes elucida os limites da participação popular nas decisões políticas locais. Para enfrentar o "problema da segurança" no bairro, a Diretoria propõe a criação de uma comissão interna composta por residentes em pontos estratégicos do bairro para mediar as denúncias perante aos órgãos competentes, através da representante da Associação que compõe o Conselho de Segurança Pública:

- A diretoria está dialogando frequentemente com a polícia militar, com a guarda, frequentemente (Nilo, então presidente da Amacentro).

- E por que, invés de ficar aí, digamos assim, postergando com criação de comissão, por que a própria diretoria não mantém esse diálogo aí com esses [órgãos] de segurança? (Seu Ricardo, morador)

- Nós já temos essa interface. Mas nós queremos abrir para mais participação (Nilo).

A ineficiência dos processos de catalização das demandas locais pelo poder público local incidirá sobre o acirramento desses conflitos. Há espaços deliberativos participativos, o problema é que a participação da sociedade civil nesses contextos serve exclusivamente a efetivação dos procedimentos de normatização do espaço, não enquanto operadores de processos de conformação de um ideal de bem comum que deverá nortear as ações. Os descontentamentos, que irão persistir ao longo do tempo, acabarão se voltando para a própria Associação: "Então, qual é a força política que a Associação tem?” (Seu Ricardo).

Depois da derrota da Chapa 2 - Renova Centro nas eleições para a diretoria da Amacentro, esse público cria uma instância alternativa de representação de moradores, apresentada publicamente como Associação Pró-Centro. Declarando explícita identificação com "valores 
familiares, da moral judaico-cristã, da liberdade do cidadão em escolher o melhor para a sua família", o movimento se propõe a representar os ideais "do patriotismo, do civismo, dos preceitos da moral, da honra, da dignidade e dos bons costumes" (VIX PRÓ-CENTRO, 2020, on-line).

Destacamos que não apenas os valores defendidos, pautados em uma delimitação restritiva dos interesses a serem representados, como também o posicionamento assumido localmente pelo grupo derrotado expressa estreita identificação com o discurso político que saiu vitorioso das eleições presidenciais ocorridas no mesmo ano no Brasil.

O mesmo público que reconhece a efetividade da Amacentro enquanto instância de representação dos moradores do bairro, ao se inscrever para disputar a diretoria da Associação, uma vez derrotado, deslegitima o processo eleitoral democrático, instituindo uma nova Associação. Ao invés de atuar nas assembleias de moradores já constituídas, participando ativamente de um processo de codefinição e de codomínio dos problemas comunitários, o grupo se dispõe a "[...] monitorar os agentes públicos a fim de impedir aprovações de atos nocivos aos interesses desta Associação" (VIX PRÓ-CENTRO, 2020, on-line, grifo nosso). A Pró-Centro se apresenta, portanto, como uma instância autônoma e independente até mesmo com relação aos interesses e às deliberações dos próprios moradores do bairro, representados pela diretoria eleita da Associação e, portanto, comprometida com a defesa de um bem de poucos, porém percebidos como um direito inalienável: o direito a uma cidade garantida.

Se o que cabe à Sociologia é analisar "[...] como os bens são percebidos nas suas ações, por meio de como esses direcionamentos do bem são avaliados pelas outras pessoas" (WERNECK, 2012, p. 245), nos deparamos com um referencial de bem que se identifica claramente com uma gramática liberal de interesses individualistas (CHEYNS; THÉVENOT, 2019). Essa pluralidade de interesses é subordinada, desse modo, a um ideal de urbanidade segundo o qual o papel do estado é administrar essa tensão, consolidando um conjunto de mecanismos que

[...] dissipem essas linhas de tensão em favor do crescente poder conferido a uma "lógica econômica e de segurança" levando ao fortalecimento de uma "abordagem do cliente" preconizada pelos órgãos de gerenciamento de projetos. (LEBOIS, 2010, p. 137 apud BREVIGLIERI, 2013, p. 220, tradução nossa $)^{27}$.

27 “affadissent cette ligne de tension au profit du pouvoir croissant accordé à une 'logique économique et sécuritaire' conduisant au renforcement d'une 'démarche client' prônée très en amont par la maîtrise d'ouvrage". 


\section{REFLEXÕES FINAIS}

O atual estado de conservação do Centro de Vitória é um problema público amplamente reconhecido localmente, a sua revitalização, ou requalificação, é mencionada nas últimas décadas em campanhas políticas, projetos de diferentes instâncias governamentais e, sobretudo, nos Planos Diretores Urbanos da cidade. O seu passado é rememorado com saudosismo pelos nativos da cidade e esse imaginário norteia os projetos direcionados para a região. Território primário de ocupação urbana e, por muitos anos, núcleo residencial, administrativo e de oferta de serviços da capital capixaba, o Centro será também o patrimônio imaterial a partir do qual serão projetados os planos de inserção da cidade, e do estado, no rol das cidades globais. As estratégias utilizadas na gestão do espaço se mostraram inefetivas ao alcance desses objetivos, sendo pautadas ainda em um modelo de gestão que se isenta do compromisso de agir como operadora de produção de bens públicos ${ }^{28}$, a partir da pluralidade de bens fundamentais ${ }^{29}$.

O potencial de mobilização coletiva observado entre os moradores do Centro de Vitória se concretiza em iniciativas de diferentes ordens que visam a solução de problemas do bairro e a melhoraria da qualidade de vida da sua população. Ao mesmo tempo, a efetivação da imagem de um "Centro Histórico" no imaginário social local estimula expectativas dos moradores de que essa região seja objeto de intervenções que promovam o restabelecimento da sua posição de centralidade na cidade, para alguns, independentemente dos meios ou das suas consequências: a remoção da população de rua para outras localidades, a repressão de práticas de expressão cultural frequentadas por um público indesejado, a especulação imobiliária e a consequente evasão da população pobre do bairro para a periferia da cidade, entre outras propostas verbalizadas em assembleias de moradores ou conversas informais com os defensores de uma modalidade de gestão do bairro mais estreitamente identificada com uma gramática liberal.

Em mutirão, os próprios moradores levantam dados, organizam festejos, promovem campanhas de conscientização, dão visibilidade às suas demandas e tornam públicos os seus problemas. Essas forças instituíram, em 20 de março de 2017, um Pacto de Convivência e Harmonia do Centro Histórico de Vitória, com o objetivo de “[...] estabelecer o diálogo sobre a utilização dos espaços públicos, privados e eventos culturais (institucionais, comunitários e comerciais), promovendo o entendimento para o bem comum" (AMACENTRO, 2017, on-

28 Nos termos de Cefaï, (2011).

29 Assim como vimos em Thévenot (2019). 
-line). O documento foi elaborado por uma comissão formada por representantes de diversos segmentos interessados, e votado pelos moradores em assembleia.

Os moradores se esforçaram para promover a neutralização das tensões prejudiciais “"[...] à tranquilidade do bairro, garantindo o respeito à separação liberal do espaço entre público e privado"30 (BREVIGLIERI, 2013, p. 233, tradução nossa). Buscam, em suas ações, a elaboração de um espaço defensivo a partir da formulação, pela própria comunidade, de garantias de convivência e "bom uso" dos espaços públicos do bairro, remontando em suas narrativas os vínculos afetivos estabelecidos com o lugar, em um esforço que reconhece a pluralidade de moralidades em coexistência e busca administrar os conflitos que dela emergem.

Ao mesmo tempo, emerge uma discursividade que tem como um dos principais eixos a diferença, traçando uma visão antagonista e que marca o contexto político brasileiro atual (CESARINO, 2019).

Observamos o agravamento dessas dissonâncias se converter em um processo de enfraquecimento do potencial de mobilização coletiva, dado que a definição de bens comuns é "“[...] indissociável das situações de debate, de controvérsia, da polêmica ou do processo no qual elementos contrários de informação, de prova e de argumentação vão ser confrontados, no qual também decisões serão consumadas" (CEFAÏ, 2011, p. 6) e carecem, assim, de um ambiente dialógico e agregador.

Sobre o princípio de uma cidade garantida se erige um modo de gestão do espaço urbano comprometido com o aprimoramento dos índices de qualidade de vida e de seus imóveis e que reivindica o compartilhamento desse valor. Ela dará a garantia daquilo que geralmente classificamos como circulação fluida: uma qualidade patrimonial, uma boa oferta de comércios, de serviços eficazes, dado nível de rentabilidade, satisfatória, aos investimentos, entre outros. Mas a constituição de um espaço referencial e informacional que sustenta a edificação da cidade garantida tende à perda de certas qualidades sensíveis. Se dissemina assim a metáfora do inferno urbano, suscitada por um tipo de angústia que incide sobre o agir humano, "[...] cativo de suas inquietudes e sua autoridade, tributária do crédito acordado a um conjunto de dispositivos normativos suscetíveis de suscitar a confiança $a^{31}$ " (BREVIGLIERI, 2013, p. 215, tradução nossa). Esses valores não são satisfeitos pelo pacto coletivo, não confiam nem se satisfazem com um acordo entre comuns, pois demandam intervenção externa e garantias estandardizadas: efeito político de uma ordem econômica liberal.

30 “à la tranquillité du voisinage en assurant le respect de la séparation libérale de l'espace entre public et privé". 31 "captif de ses inquiétudes, et son autorité, tributaire du crédit accordé à un ensemble de dispositifs tiers susceptibles de susciter de la confiance". 
Eficiente ou não em termos do alcance dos seus objetivos, a modalidade de gestão urbana vigente na cidade de Vitória também contribui para a conformação de uma atmosfera na qual a pluralidade de bens fundamentais é subordinada a uma governabilidade pela norma, visando a promoção de um bairro histórico (não um bairro vivido, mas mero produto).

\section{REFERÊNCIAS}

1. AMACENTRO. Pacto de Convivência e Harmonia do Centro Histórico de Vitória. 20 mar. 2017. Disponível em: https://drive.google.com/file/ d/0B05i6MFyaz0XcU5zeWtYSVJuakU/view?fbclid=IwAR3LVxNdq8MkEDfBMqA CwlQyY6Yr4hCIO-JSiUOsyTplNs24VhlO-aGshQE. Acesso em: 22 set. 2017.

2. BOLTANSKI, L.; CHIAPELLO, È. O novo espírito do capitalismo. São Paulo: Martins Fontes, 2009.

3. BOTELHO, T. R. Revitalização de centros urbanos no Brasil: uma análise comparativa das experiências de Vitória, Fortaleza e São Luís. Revista Eure, Santiago de Chile, v. 31, n. 93, p. 53-71, 2005. Disponível em: https://scielo.conicyt.cl/pdf/eure/v31n93/ art04.pdflink. Acesso em: 17 abr. 2015.

4. BREVIGLIERI, M. Une brèche critique dans la ville garantie? Espaces intercalaires et architectures d'usage. In: LANZA COGATO, E.; PATTARONI, L.; PIRAUD, M.; TIRONE, B. De la différence urbaine: le quartier des Grottes, Genève. Genève: Mettis Presses, 2013.

5. CAMPOS, D. S. Ponte da passagem: por significações. 2016. 160 f. Orientadora: Moema Lúcia Martins Rebouças. Dissertação (Mestrado) - Programa de PósGraduação em Comunicação e Territorialidades, Universidade Federal do Espírito Santo, Vitória, 2016. Disponível em: http://repositorio.ufes.br/bitstream/10/7081/1/ tese_9954_Disserta\%c3\%a7\%c3\%a3o\%20final\%20para\%20impress $\%$ c3\%a3o $\% 20$ -\%20REVISADA\%20PDF.pdf. Acesso em: 04 maio 2019.

6. CAMPOS JÚNIOR, C. T. A construção da cidade: formas de produção imobiliária em Vitória. Vitória: Florecultura, 2002.

7. CEFAÏ, D. Públicos, problemas públicos, arenas públicas... O que nos ensina o pragmatismo (Parte 1). Novos Estudos CEBRAP, São Paulo, v. 36, n. 1, p. 187-213, 2017a. Disponível em: https://www.icomfloripa.org.br/wp-content/uploads/2018/06/ Cefai2017-PARTE-1-obrigatoria.pdf. Acesso em: 25 jun. 2018.

8. CEFAÏ,D.Públicos, problemaspúblicos, arenaspúblicas...Oquenosensinaopragmatismo 
(Parte2).NovosEstudos CEBRAP,SãoPaulo,v.36,n.2,p.129-142,2017b.Disponívelem: https://www.scielo.br/j/nec/a/cGMgGqgT94BFhsXst8Shp4L/?lang=pt\&format=pdf. Acesso em: 25 jun. 2018.

9. CEFAÏ, D. Como uma associação nasce para o público: vínculos locais e arena pública em torno da associação La Bellevilleuse em Paris. In: CEFAÏ, D. et al. (org.). Arenas públicas: por uma etnografia da vida associativa. Niterói: EdUFF, 2011.

10. CEFAÏ, D. Como nos mobilizamos? A contribuição de uma abordagem pragmatista para a sociologia da ação coletiva. Revista Dilemas, Rio de Janeiro, v. 2, n. 4, p. 11-48, 2009. Disponível em: https://revistas.ufrj.br/index.php/dilemas/article/view/7163/5742. Acesso em: 10 out. 2015.

11. CESARINO, L. Identidade e representação no bolsonarismo: corpo digital do rei, bivalência conservadorismo-neoliberalismo e pessoa fractal. Revista de Antropologia, São Paulo, v. 63, n. 1, p. 530-557, 2019. Disponível em: https://www.revistas.usp.br/ra/ article/view/165232/158421. Acesso em: 10 out. 2020.

12. CHEYNS, E.; THÉVENOT, L. Le gouvernement par standards de certification consentement et plaintes des communautés affectées. La Revue des droits de l'homme, n. 16, p 1-33, 2019. Disponível em: https://journals.openedition.org/revdh/6843. Acesso em: 04 dez. 2020.

13. DEFENSORIA PÚBLICA DA UNIÃO. Prefeito de Vitória é intimado a cadastrar ocupantes de antigo prédio do IAPI. 2017. Disponível em: https://dpu.jusbrasil.com. br/noticias/473857456/prefeito-de-vitoria-e-intimado-a-cadastrar-ocupantes-de-antigopredio-do-iapi?ref=serp. Acesso em: 14 jun. 2020.

14. GAZETA ONLINE. Audiência pública discute proposta de fechar bares em Vitória após 2 da manhã. Gazeta Online, 11 maio 2015. Disponível em https://www.gazetaonline. com.br/noticias/cidades/2015/05/audiencia-publica-discute-proposta-de-fechar-baresem-vitoria-apos-2-da-manha-1013896710.html. Acesso em: 14 jun. 2020.

15. GAZETA ONLINE. Aeroporto de Vitória terá quatro novos voos na temporada de verão. Gazeta Online, 01 dez. 2020. Disponível em: https://www.agazeta.com.br/es/economia/ aeroporto-de-vitoria-tera-quatro-novos-voos-na-temporada-de-verao-1220. Acesso em: 14 dez. 2020.

16. GAZETA ONLINE. Centro tem "cadeiraço" contra fechamento de bares às 23 horas. Gazeta Online, 17 mar. 2017. Disponível em: https:/www.gazetaonline.com.br/ noticias/cidades/2017/03/centro-tem-cadeiraco-contra-fechamento-de-bares-as-23horas-1014035184.html. Acesso em: 18 maio 2020.

17. G1. Ato no Centro de Vitória faz cortejo de sambista contra 'morte dos bares'. G1, 18 mar. 2017. Disponível em: http://g1.globo.com/espirito-santo/noticia/2017/03/ato-nocentro-de-vitoria-faz-cortejo-de-sambista-contra-morte-dos-bares.html. Acesso em: 03 jun. 2020. 
18. G1. Samba é realizado como protesto na Rua Sete, no Centro de Vitória. G1, 17 set. 2016. Disponível em: http://g1.globo.com/espirito-santo/noticia/2016/09/samba-e-realizadocomo-protesto-na-rua-sete-no-centro-de-vitoria.html. Acesso em: 15 jun. 2020.

19. GLUCKMAN, M. Gossip and Scandal. Current Anthropology, Chicago, v. 4, n. 3, p. 307-316, 1963. Disponível em: https://www.romolocapuano.com/wp-content/ uploads/2017/12/Gossip-and-Scandal-Max-Gluckman.pdf. Acesso em: 02 maio 2021.

20. GOMES, E. A modernização urbana do Centro de Vitória (ES): considerações preliminares sobre a geografia do passado de uma cidade. Geografares, v. 6, p. 73-87, 2008. Disponível em: https://periodicos.ufes.br/geografares/article/view/1017. Acesso em: 07 jul. 2016.

21. GOVERNO DO ESTADO DO ESPÍRITO SANTO. Aeroporto de Vitória amplia opções de voos a partir desta semana. Vitória, 2020. Disponível em: https://www. es.gov.br/Noticia/aeroporto-de-vitoria-amplia-opcoes-de-voos-a-partir-desta-semana. Acesso em: 15 dez. 2020.

22. INSTITUTO GOIA. Visitar. Vitória, 2015. Disponível em: http://www.institutogoia. org/pg/2996/projeto-visitar/. Acesso em: 03 jul. 2015.

23. MAGNANI, J. G. MAGNANI, J. C. Quando o campo é a cidade. In: Magnani, J. C.; TORRES, L. L. (org.). Na metrópole - Textos de Antropologia Urbana. São Paulo: EDUSP, 1996.

24. MAGNANI, J. G. MAGNANI, J. C. Rua, símbolo e suporte da experiência urbana. Cadernos de História de São Paulo, n. 2, p. 1-14, 1993. Disponível em: https:// nau.fflch.usp.br/sites/nau.fflch.usp.br/files/upload/paginas/rua_simbolo $\% 20 \mathrm{e} \% 20$ suporte\%20da\%20experiencia\%20-\%20magnani.pdf. Acesso em: 15 jun. 2019.

25. MENDONÇA, E. M. S.; FREITAS, J. F. B.; CAMPOS, M. M.; PRADO, M. M.; ALMEIDA, R. H. et al. Cidade prospectiva: o projeto de Saturnino Brito para Vitória. Vitória: EDUFES; Annablume, 2009.

26. MOTA, F. R. O meio ambiente contra a sociedade? Controvérsias públicas, reconhecimento e cidadania no Brasil. DILEMAS: Revista de Estudos de Conflito e Controle Social. v. 7, n. 1, p. 39-57, 2014. Disponível em: https://revistas.ufrj.br/index. php/dilemas/article/view/7251/5831. Acesso em: 14 dez. 2020.

27. NÉSPOLI, A. A.; BLANC, M. Políticas de desenvolvimento urbano na cidade de Vitória: uma história recente. In: VASCONCELLOS, F.; BLANC, M. (org.). Reflexões sobre o urbano no Espírito Santo: desenvolvimento, expansão e experiências urbanas. Florianópolis: Insular, 2016.

28. NÉSPOLI, A. A. Qual é o rock hoje?: empreendedorismo cultural no centro de VitóriaES. 2016. 138. Orientadora: Manuela Vieira Blanc. Dissertação (Mestrado em Sociologia Política) - Universidade Vila Velha, Vila Velha, 2016. Disponível em: https://repositorio. uvv.br/bitstream/123456789/167/1/DISSERTA\%c3\%87\%c3\%83O\%20FINAL\%20 
DE\%20AMANDA\%20ALVARENGA\%20NESPOLI.pdf. Acesso em: 28 jun. 2018.

29. PARK, R. A cidade: Sugestões para a investigação do comportamento humano no meio urbano. In: VELHO, O. G. O fenômeno urbano. Rio de Janeiro: Zahar, 1979.

30. REIS, L. C. T. Descentralização e desdobramento do núcleo central de negócios na cidade capitalista: estudo comparativo entre Campo Grande e Praia do Canto, na Grande Vitória-ES. 2007. 286 f. Orientador: Roberto Lobato Corrêa. Tese (Doutorado) - Departamento de Geografia, Universidade Federal do Rio de Janeiro, Rio de Janeiro, 2007. Disponível em: objdig.ufrj.br/16/teses/680831.pdf. Acesso em: 21 maio 2018.

31. SÉCULO DIÁRIO. Eleição da Amacentro consolida derrota do grupo do prefeito. Século Diário, 14 ago. 2018. Disponível em: https:/www.seculodiario.com.br/cidades/eleicaoda-Amacentro-consolida-derrota-do-grupo-do-prefeito. Acesso em: 15 maio 2020.

32. THÉVENOT, L. A New Calculable Global World in the Making: Governing through Transnational Certification Standards. In: MENNICKEN, A.; SALAIS, R. (ed.). The New Politics of Numbers: Quantification, Administrative Capacity and Democracy. London: Palgrave Macmillan, 2019.

33. THÉVENOT, L. Autorités à l'épreuve de la critique. Jusqu'aux oppressions du 'gouvernement par l'objectif'. In: BRUNO, F. Le tournant de la théorie critique. Paris: Desclée de Brouwer, 2015. p. 216-235.

34. THÉVENOT, L. Autorités à l'épreuve de la critique. Des évaluations autorisées et de leurs critiques jusqu'aux oppressions du “gouvernement par l'objectif”. In: BRUNO, F. (ed.). Quel présent pour la critique sociale? Paris: Desclée de Brouwer, 2013.

35. THÉVENOT, L. Sacrifices et bénéfices de l'individu dans un espace public libéral. Cahiers d'éthique sociale et politique, n. 5, p. 68-79, 2008. Disponível em: https://www. researchgate.net/publication/305389574_Sacrifices_et_benefices_de_1\%27individu_ dans_un_espace_public_liberal Acesso em: 14 dez. 2020.

36. THÉVENOT, L. Un gouvernement par les normes: pratiques et politiques des formats d'information. In: CONEIN, B.; THÉVENOT, L. (Ed.) Cognition et information en société. Paris : Éditions de l'École des hautes études en sciences sociales, 1997. p. 205241.

37. VITÓRIA. Plano de Desenvolvimento Urbano da cidade de Vitória - ES. Disponível em: https://www.vitoria.es.gov.br/arquivos/20180627_seminario_pdu_final.pdf. Acesso em: 03 jun. 2020.

38. TRIBUNA ONLINE. Depois de deixar IAPI, quarenta famílias ocupam outro prédio no Centro de Vitória. Tribuna Online, 25 jul. 2017. Disponível em: https://tribunaonline. com.br/depois-de-deixar-iapi-quarenta-familias-ocupam-outro-predio-no-centro-devitoria. Acesso em: 07 maio 2020.

39. TRINDADE, F. C. Multiplicidade: o lugar da habitação nas intervenções em áreas 
centrais. 2015. 152 f. Martha Machado Campos. Dissertação (Mestrado em Arquitetura e Urbanismo) - Universidade Federal do Espírito Santo, Vitória, 2015. Disponível em: http://repositorio.ufes.br/jspui/handle/10/4436. Acesso em: 23 maio 2016.

40. VIX PRÓ CENTRO. Centro de Vitória: seu guia do Centro. 2020. Disponível em: http://www.centrodevitoria.com.br/pgn/2590954/associacoes-vix-pro-centro/. Acesso em: 20 fev. 2020.

41. WALDETÁRIO, K. Z. Diretrizes para aplicação dos conceitos de sustentabilidade na reabilitação de edifícios em centros urbanos para fins de habitação popular: análise do programa morar no Centro - Vitória (ES). 2009. 178 f. Orientador: Cristina Engel de Alvarez. Dissertação (Mestrado em Arquitetura e Urbanismo) - Universidade Federal do Espírito Santo, Vitória, 2009. Disponível em: https://lpp.ufes.br/sites/lpp. ufes.br/files/field/anexo/dissert3478423.pdf. Acesso em: 20 maio 2019.

42. WERNECK, A. A desculpa: as circunstâncias e a moral das relações sociais. Rio de Janeiro: Civilização Brasileira, 2012.

43. VISITAR. Comunicado. Facebook, Vitória, 29 dez. 2015. Disponível em: https://www. facebook.com/visitarvitoria/photos/a.450831524930748/1289745901039302/?type=3 \&theater. Acesso em: 16 maio 2020.

\section{Manuela Vieira Blanc}

Doutora em Sociologia Política pela Universidade Estadual do Norte Fluminense Darcy Ribeiro. Coordenadora do Grupo de Pesquisa Cidades, Espaços Públicos e Periferias e do Projeto Cep 29: Núcleo capixaba de estudos da experiência humana em meio urbano. Professora do Departamento de Ciências Sociais da Universidade Federal do Espírito Santo. ID ORCID: http:// orcid.org/0000-0003-0595-7875. E-mail: manu_uenf@yahoo.com.br. 